\title{
UPAYA KONSERVASI EKS-SITU FAMILI BEGONIACEAE DARI TAMAN NASIONAL BUKIT BARISAN SELATAN DI KEBUN RAYA LIWA, KABUPATEN LAMPUNG BARAT, PROVINSI LAMPUNG
}

\author{
Esti Munawaroh ${ }^{1)}$, Hartutiningsih M. Siregar ${ }^{2)}$ \\ ${ }^{1,2)}$ Pusat Konservasi Tumbuhan Kebun Raya-LIPI, Bogor \\ 1)email: munawaroh.esti@yahoo.com \\ Diterima 15 Februari 2018 disetujui 24 April 2018
}

\begin{abstract}
Begoniaceae is one of the largest families in Angiospermae that has economic value, for ornamental plants and traditional medicine. In Bukit Barisan Selatan Nasional Park (TNBBS), there are many species of Begonia that are relatively abundant in population. Conservation efforts need to be done, due to the destruction of continuous forest areas that lead to reduced biodiversity of Begonia plant species. Exploration activities have been undertaken to collect the various species of Begoniaceae in TNBBS, and then planted in Liwa Botanical Garden located in Liwa, West Lampung. As a conservation effort several studies have been conducted to adapt some Begonia species. From the exploration results have been obtained 8 types of Begonia is Begonia atricha (Miq.) Miq. ex A.DC, B. areolata Miq., B.cf. bracteata, B. isoptera Dryand ex. Sm.B.cf. vuijekii Koord, B.cf. scottii Tebbit ,. B. lepida Blumedan B. muricata Blume.
\end{abstract}

Keywords: Conservation, Begoniaceae, Liwa Botanical Garden

\section{PENDAHULUAN}

Keanekaragaman jenis dan plasma nutfah tanaman hias asli Indonesia sangat penting terutama sebagai modal dasar untuk pemuliaan. Terkait dengan hal tersebut maka inventarisasi kekayaan jenis tanaman hias asli Indonesia perlu dilakukan agar dapat dimanfaatkan terutama dalam usaha meningkatkan kualitas dan kuantitas tanaman hias asli Indonesia. Upaya yang demikian dapat menambah dan meningkatkan usaha penganekaragaman jenis tanaman hias yang dapat diberdayakan di Indonesia. Untuk menjaga kelestarian jenis-jenis tumbuhan liar yang belum tersentuh potensi pemanfaatannya termasuk yang berpotensi sebagai tanaman hias, maka Kebun Raya Liwa merupakan salah satu wadah yang tepat untuk tujuan tersebut. Terkait dengan hal itu, menurut (Purwantoro, 2009) mengemukakan bahwa upaya pengkoleksian jenis-jenis tumbuhan liar dari habitat aslinya merupakan langkah awal dalam upaya domestikasi menurut . Tumbuhan liar dikonservasi secara eks situ untuk mengaklimatisasikan dengan kondisi lingkungan di luar habitat alam, yaitu dengan menerapkan teknik pemeliharaan secara intensif yang telah dibakukan.

Indonesia masih banyak memiliki jenis-jenis tumbuhan liar yang berpotensi sebagai tanaman hias, selain anggrek. Hal ini perlu dikaji dengan lebih dalam sebagai salah satu upaya pengembangan potensi keanekaragaman hayati Indonesia. Begoniaceae, merupakan salahsatu suku tumbuhan yang pada beberapa tahun terakhir mulai menjadi trend. Kelompok tanaman inimasih belum tersentuh oleh industri florikultura. Untuk menggali potensinya perlu didukung kegiatan eksplorasi, koleksi dan konservasi yang berkesinambungan sebagai dasar pengembangan jenis-jenis berpotensi.

Keanekaragaman jenis Begoniaceae yang ada di dunia diperkirakan lebih dari 1.825 jenis yang tersebar di kawasan tropik dan subtropik Asia, Amerika dan Afrika (Kiew, 2005. Kiew, Sang, Repin, Ahmad, 2015). 
Indonesia merupakan salah satu pusat sumber keragaman plasma nutfah Begoniadi kawasan Asia Tenggara, jumlah saat ini diperkirakan mencapai lebih dari 200 jenis yang tersebar di seluruh pulau-pulau besar dan beberapa pulau kecil, yaitu 15 jenis di Jawa, 44 Jenis di Sulawesi, Sumatera 63 jenis, Kalimantan 8 jenis, Sulawesi 44 jenis dan Irian 70 jenis (Kiew, Sang, Repin, Ahmad, 2015]. Tumbuhan Begonia dapat ditemukan pada tipe habitat yang berbeda, antara lain perbukitan karst dan hutan hujan tropik dataran rendah hingga pegunungan berketinggian sampai 2.400 m dpl.

Bukit Barisan Selatan National Park adalah salah satu taman nasional di Indonesia yang memiliki berbagai jenis vegetasi hutan, seperti hutan mangrove, hutan pantai, pamah hutan tropis, dengan hutan pegunungan yang terletak di wilayah Sumatera. Letaknya yang membentang dari Provinsi Bengkulu, berikut pegunungan Bukit Barisan ke selatan dan provinsi selatan Lampung (Dephut. 2011). Pada awal pembentukan itu pada tahun 1982, itu seluas $3.568 \mathrm{~km} 2$, namun sekarang berkurang menjadi $3.240 \mathrm{~km} 2$. Laporan dari World Wildlife Fund (WWF) menyebutkan bahwa 70\% dari luas hutan di Bukit Barisan Selatan pada tahun 2010 berubah menjadi lahan pertanian dan pemukiman. Keragaman spesies Begonia di TNBBS belumpernah dilaporkan, dari kegiatan eksplorasi ini bertujuan untuk konservasi secara eks situ dan ditanam di Kebun Raya Liwa, KabupatenLampung Barat, Provinsi Lampung.

\section{METODE}

Kegiatan eksplorasi, inventarisasi, dan koleksi dilakukan dengan metode jelajah secara acak terwakili (eksploratif). Kawasan yang dijelajahi Resort Kubu Perahu, Resort Sukaraja Atas, Resort Pugung Tampak TNBBS dan kawasan Hutan Lindung Rigis 45B, dengan melakukan koleksi berbagai jenis dari suku Begoniaceae. Setiap jenis yang dikoleksi kemudian diberi label gantung, semua data dan informasi tentang tumbuhan yang dikoleksi beserta data lingkungan dicatat dalam buku lapangan. Data tersebut berisikan nama jenis, suku, kondisi tempat hidup, ketinggian (altitude), posisi lintang dan bujur, data morfologi. Pengkoleksian mengacu pada protokol koleksi hidup dari Kebun Raya Bogor

Pemeliharaan koleksi berupa anakan selama di lapangan adalah sebagai berikut dilakukan penyungkupan dengan menggunakan kantong plastik dengan ukuran 100 x $50 \mathrm{~cm}$ untuk menjaga kelembaban. Setelah koleksi di bawa ke Kebun Raya Liwa dilakukan proses aklimatisasi yakni tanaman diaklimatisasi di rumah kaca pembibitan, ditanam di pot plastik diameter $25 \mathrm{~cm}$ dengan media tanah dan kompos perbandingan 1:1, kelembaban cukup, disungkup plastik selama 90 hari sampai terbentuk tunas, sungkup dibuka dan dibiarkan sampai pertumbuhannya normal. Penyiraman dilakukan seperlunya dengan cara plastik dibuka.

Pembuatan spesimen herbarium sesuai dengan metofde yang telah dikemukakan oleh Rugayah et al., (2004). Pembuatan herbarium yang baik bila materialnya lengkap meliputi, daun, bunga dan buah. Dicatat data lapang mencakup nama daerah, manfaat, habitat, ekologi, perawakan, dan warna, Dilakukan pendokumentasian (foto) guna melengkapi dan mendukung data.

\section{HASIL DAN PEMBAHASAN}

\section{Keanekaragaman Begonia spp. di Kawasan Taman Nasional Bukit Barisan Selatan}

Kegiatan koleksi dan penelitian yang dilakukan pada ketinggian 
antara100 - $1300 \mathrm{~m}$ dpl.,menunjukkan bahwa kawasan tersebut masih bagus kondisi hutannya. Jenis tumbuhan yang banyak dijumpai adalah dari suku Annonaceae, Myrtaceae dan Melliaceae. Semakin ke puncak kondisi kawasan semakin tebal humusnya. Kemiringan lereng hampir $75 \%$, sehingga ketebalan humus sering terkikis oleh air hujan. Kawasan dengan temperatur dan kelembaban yang cukup tinggi terebut menyebabkan banyak pohon yang ditumbuhi oleh lumut dan bebatuan yang berlumut. Disamping itu di tempat ini banyak dijumpai jenis tumbuhan hias yang unik dan menarik pada kawasan yang lembab dan ternaungi. Kawasan ini walaupun lembab tetapi matahari masih dapat menembus kelebatan hutan.

Koleksi Begonia spp. yang ditemukan di lokasi penelitian di kawasan Taman Nasional Bukit Barisan Selatan, dari 3 kabupaten yaitu: a). Resort Kubu Perahu, Kabupeten lampung Barat, b). Resort Sukaraja Atas, Kabupeten
Tanggamus dan c). Resort Pugung Tampak, Kabupaten Pesisir Barat, dalam kondisi yang relatip baik berhasil didapatkan dan telah diidentifikasi sampai tingkat jenis sebanyak 8 nomor antara lain Begonia atricha (Miq.) Miq. ex A.DC, B. areolata Miq., B.cf. bracteata, $B$. isoptera Dryand ex. Sm.B.cf. vuijekii Koord, B.cf. scottii Tebbit,. B. lepida Blumedan B. muricata Blume, (Dephut. 2011; HartutiningsihM.Siregar, 2017; Kiew, Sang, Repin, Ahmad. 2015; Smith, Wasshausen, Golding, Karegeannes, 1986), seperti pada Tabel 1.

Jenis Begonia spp. yang kita dapatkan mempunyai beberapa perawakan adalah Jenis Begonia yang tumbuh tegak dan bercabang antara lain B. areolata, B. atricha, B.cf. vuijekii dan $B$. isoptera Sedangkan Begonia yang tumbuh batang merayap ditanah antara lain B. muricata, B.cf. scottii, B. lepidadan B.cf. bracteata.

Tabel 1. Jenis-jenis Begonia spp. di Kawasan Taman Nasional Bukit Barisan Selatan

\begin{tabular}{|c|c|c|c|c|c|}
\hline \multirow[b]{2}{*}{ Nama Ilmiah } & \multirow[b]{2}{*}{ Habitus/perawakan } & \multicolumn{4}{|c|}{ Kawasan/Resort } \\
\hline & & $\begin{array}{l}\text { Balik } \\
\text { Bukit }\end{array}$ & $\begin{array}{c}\text { Suka } \\
\text { raja } \\
\text { Atas }\end{array}$ & $\begin{array}{l}\text { Pugung } \\
\text { Tampak }\end{array}$ & $\begin{array}{c}\text { Rigis } \\
45\end{array}$ \\
\hline Begonia lepida Blume & Tumbuhan merayap & $\mathrm{v}$ & - & $\mathrm{v}$ & - \\
\hline Begonia areolata Miq. & Tumbuhan tegak & $\mathrm{v}$ & - & - & $\mathrm{v}$ \\
\hline Begonia cf. bracteata & $\begin{array}{l}\text { Tumbuhan } \\
\text { merayap }\end{array}$ & - & $\mathrm{v}$ & - & - \\
\hline Begonia cf. vuijekii Koord & Tumbuhan tegak & - & $\mathrm{v}$ & - & - \\
\hline Begonia cf. scottii Tebbit & Tumbuhan merayap & - & - & - & $\mathrm{v}$ \\
\hline Begonia atricha(Miq.) Miq. ex A.DC & Tumbuhan tegak & - & - & - & $\mathrm{v}$ \\
\hline Begonia isoptera Dryand ex. Sm. & Tumbuhan tegak & - & - & - & $\mathrm{v}$ \\
\hline Begonia muricata Blume & $\begin{array}{l}\text { Batang merayap } \\
\text { ditanah }\end{array}$ & - & - & - & $\mathrm{v}$ \\
\hline
\end{tabular}

Pada umumnya jenis-jenis Begonia sangat menyukai naungan. Faktor lingkungan abiotik seperti suhu, kelembaban dan ketinggian sangat berperan penting dan sangat mempengaruhi pertumbuhan dan keberadaan Begonia di alam. Pada tabel 2 dapat dilihat peta persebaran Begonia di 
TNBBS paling banyak ditemukan pada ketinggian 700-1100 m dpl. Di bawah $700 \mathrm{~m}$ dpl, keragamannya mulai berkurang. Data lingkungan yang diperoleh menunjukkan bahwa pada ketinggian 100-500 m dpl. suhu berkisar antara $23-32^{\circ} \mathrm{C}$ dan kelembaban udara berkisar antara 50-100\%.

Begonia paling sedikit ditemukan pada kawasan Resort Pugung Tampak yaitu hanya satu jenis. Kawasan ini memiliki topografi berbukit-bukit, dengan ketinggian 100-400 m. dpl., suhu $24^{\circ}-30^{\circ} \mathrm{C}$ dan kelembaban 55\%-90\%.
Kondisi kawasan yang cenderung panas kurang cocok bagi pertumbuhan Begonia, sehingga keragaman jenis Begonia yang ditemukan pun sangat sedikit. Kemelimpahan jenis Begonia paling banyak ditemukan di Resort Rigis 45 ada lima jenis. Hal ini disebabkan karena kondisi mikroklimat di kawasan ini sangat sesuai untuk tumbuh kembangnya jenis-jenis Begonia. Salah satu jenis yang dapat tumbuh sampai dengan ketinggian $1300 \mathrm{~m}$ dpl adalah $B$. areolata Miq. Jenis ini ditemukan pada kedua lokasi resort yang diteliti (Tabel 2).

Tabel 2. Jumlah Jenis Begonia ditemukan pada empat resort berdasarkan ketinggian, temperatur dan kelembaban udara

\begin{tabular}{lcccc}
\hline \multicolumn{1}{c}{ Lokasi } & $\begin{array}{c}\text { Ketinggian } \\
(\mathrm{m} \mathrm{dpl})\end{array}$ & $\begin{array}{c}\text { Temperatur } \\
\text { udara }\left({ }^{\circ} \mathrm{C}\right)\end{array}$ & $\begin{array}{c}\text { Kelembaban } \\
\text { udara }(\%)\end{array}$ & $\begin{array}{c}\text { Jumlah jenis yang } \\
\text { ditemukan }\end{array}$ \\
\hline Resort Balik Bukit & $580-1300$ & $20^{\circ}-23^{\circ}$ & $80-100$ & 2 \\
Resort Sukaraja Atas & $600-700$ & $28^{\circ}-29^{\circ}$ & $83-88$ & 2 \\
Resort Pugung & $100-400$ & $24^{\circ}-30^{\circ}$ & $55-90$ & 1 \\
Tampak & $700-1100$ & $21^{\circ}-27^{\circ}$ & $60-100$ & 5 \\
Resort Rigis 45 & & & & \\
\hline
\end{tabular}

Pertelaan Begonia spp (Begoniaceae) di Kawasan Taman Nasional Bukit Barisan Selatan

\section{a. Begonia areolata Miq.}

Herba tegak, tinggi mencapai $1,5 \mathrm{~m}$.

Batangberbuku-buku, tiap buku keluar dua tangkai daun,panjang buku $10-30 \mathrm{~cm}$. Daun tunggal, bundar telur,pangkal daun menjantung tidak simetris, tepi berlobusdangkal makin ke ujung bergerigi, ujung daunmeruncing, permukaan atas hijau kekuningan sampaikemerahan berbingkul-bingkul dan berbulu kasarpanjang, permukaan bawah hijau keputihan berbulurapat warna merah di sepanjang peruratan daun, daunmuda berbulu rapat merah, ukuran daun $11-15 \times 15-20 \mathrm{~cm}$; tangkai daun 5-25 $\mathrm{cm}$. Tipe perbungaan majemukterbatas; panjang tangkai perbungaan 15-20 cm. Bungajantan memiliki 4 buah tenda bunga berwarna putih, tangkai bunga $3 \mathrm{~cm}$. Bungabetina memiliki 5 buah tenda bunga. Buah buni, beruang 3 yangdibatasi oleh sekat, bersayap 3 satu lebih panjang,berbingkulbingkul dan berbulu kasar. Jenis ini merupakan jenis yang pertumbuhannya meninggi, daunnya kompak, bunganya berwarnaputih cocok sebagai tanamanhias halaman rumah maupun tanaman pot.

Habitat tumbuh di tempat lembab dipinggiran sungai, agak ternaungi, pada ketinggian $750 \mathrm{~m}$ dpl., temperatur udara saat itu $20-23^{\circ} \mathrm{C}$, dengan kelembaban udara $80-100 \%$. Distribusi diketemukan di Resort Balik Bukit dan Resort Rigis 45, Taman Nasional Bukit Barisan Selatan.

b. Begonia atricha (Miq.) Miq. ex A.DC

Pertelaan: Herba tegak, tinggi mencapai $1,5 \mathrm{~m}$. batang beruas, berwarna hijau kemerahan.Daun tunggal, bundar telur sampai oblong, asimetris, 
permukaan keperakan bercak putih, tepi bergerigi, pangkal dauntidak simetris, ujung melancip, ukuran 6-8 x $4-6$ $\mathrm{cm}$;tangkai daun 2-5 cm. Bunga berwarna putih,tangkai bunga $1-1,5 \mathrm{~cm}$ benang sari kuning. Bunga betina putih. Buah kapsul, sayap 3. Begonia ini juga ditemukan di Pagaralam dan kawasan hutan di Sumatera. Keunikan tumbuhan ini adalah memiliki dua bentuk, yakni pada saat muda, permukaan daun atas memiliki bintik-bintik bercak putih di seluruh permukaannya, sedangkan pada saat menua bintik-bintik tersebut hilang. Memiliki potensi sebagai tumbuhan ornamental atau hias karena memiliki bentuk dan pola warnanya yang menarik, juga potensi herbal yaitu sebagai penghilang racun dalam tubuh dan membantu memperbaiki sirkulasi darah. Secara ekologi, tumbuhan ini dapat dijadikan indikator keberadaan air atau sungai bersih.

Habitat ditemukan paga ketinggian 700-1100 $\mathrm{m}$ dpl., temperatur udara saat itu $20-23^{\circ} \mathrm{C}$, dengan kelembaban udara 60-100\%. Distribusi Resort Rigis 45 Taman Nasional Bukit Barisan Selatan

\section{c. Begonia cf. bracteata}

Herba merayap dengan ujung tegak, tinggisampai $25 \mathrm{~cm}$. Batang jarang bercabang, stipula jelas bentuk segitiga agak membulat berwarna hijau. Daun bundar telur sampai oval, berwarna hijau, berbulu halus, pangkal berlekuk tidak simetris, ujung meruncing, ukuran daun lebih besar dari jenis B. lepida 6-11 x 4$7,5 \mathrm{~cm}$; tangkai daun pendek $0,5-1,5 \mathrm{~cm}$. Tangkai perbungaan 2-4 cm. Bunga jantan berwarna merah, benang sari kuning. Bunga betina merah muda. Buah bersayap 3, berwarna merah, berbulu, beruang 3 dengan sekat. Jenis ini merupakan jenis yang menjalar cocok sebagai tanaman hias dalam pot gantung.
Habitat banyak dijumpai pada ketinggian antara 600-700 m dpl.temperatur udara saat itu $28-29^{\circ} \mathrm{C}$, dengan kelembaban udara $83-88 \%$. Distribusi Resort Sukaraja Atas, kawasan Taman Nasional Bukit Barisan Selatan

\section{d. Begonia cf. scottii Tebbit}

Herba merayap, tinggi sampai 50 cm. Batan gberbuku-buku pendek, Daun bundar telur, pangkal menjantung tidak simetris, ujung meruncing, permukaan atas daun berwarna hijau mengkilap, ukuran 15-30 x 10-20 cm; tangkai daun $25-30 \mathrm{~cm}$, berbulu. Daun muda berwarna merah berbulu halus. Tipe perbungaan anak payung menggarpu majemuk; bunga jantan berwarna putih benangsari kuning, bungabetina putih, tangkai perbungaan $10-15 \mathrm{~cm}$, berbulu.

Habitat banyak dijumpai pada ketinggian antara 600-700 m dpl. temperatur udara saat itu $28-29^{\circ} \mathrm{C}$, dengan kelembaban udara 83-88\%. Distribus di Resort Sukaraja Atas, kawasan Taman Nasional Bukit Barisan Selatan

\section{e. Begonia cf. vuijekii Koord}

Pertelaan: Herba tegak, panjang mencapai $30 \mathrm{~cm}$. Batang licin berruas. Daun membulat, pangkal berlekuk menjantung tidak simetris, ujung meruncing, permukaan atas hijau mengkilat dengan urat daun yang nyata, ukuran daun diameter 7-10 cm;tangkai daun 3-5 cm. Bunga jantan kemerahan, bunga betina merah, tangkai bunga 1-1,5 $\mathrm{cm}$. Buah bersayap 3.Jenis ini cukup menarik karena daun yang kompak dan warna bunga kemerahan baik sebagai tanaman hias dalam pot. Habitat: ditemukan pada ketinggian 700-1100 m dpl., temperatur udara saat itu $20-23^{\circ} \mathrm{C}$, dengan kelembaban udara 60-100\%. Distribusi: Resort Rigis 45 Taman Nasional Bukit Barisan Selatan 
f. Begonia isoptera Dryand ex. Sm.

Pertelaan: Herba tegak, batang berbuku-buku licin, tinggisampai $1 \mathrm{~m}$. Daun tunggal, bundar telur sampai oblong,permukaan licin, tepi bergerigi tersebar, pangkal daun tidak simetris, ujung melancip, ukuran 2-8 x 4-21 cm; tangkai daun $0,5-5 \mathrm{~cm}$. Tipe perbungaan majemuk terbatas; panjang tangkai perbungaan 3,5-4 cm. Bungajantan memiliki 2 tenda bunga warna putih,tangkai bunga $1-1,5 \mathrm{~cm}$ benang sari kuning. Bunga betina memiliki 5 tenda bunga. Buah kapsul, sayap 3 sama panjang,beruang 3, tangkai buah 2-2,5 cm.Jenis ini merupakan jenis yang pertumbuhannya meninggi, daunnya kompak, bunganya berwarna putih cocok sebagai tanaman hias pekarangan.

Habitat di bawah naungan hutan primer sampai ketinggian $1100 \mathrm{~m}$ dpl. Distribusi diketemukan di Resort Balik Bukit dan Resort Rigis 45, Taman Nasional Bukit Barisan Selatan

\section{g. Begonia lepida Blume}

Pertelaan: Herba merayap dengan ujung tegak, tinggisampai $25 \mathrm{~cm}$. Batang jarang bercabang, berbuku-buku. Daun bundar telur sampai oval, pangkal berlekuk tidak simetris, pinggir bergerigi, ujung meruncing, ukurandaun kecil 6-11 x 3-5,5 cm; tangkai daun pendek 0,6-2,2 $\mathrm{cm}$. Tipe perbungaan majemuk tidak terbatas (racemosa); tangkaiperbungaan $5,2 \mathrm{~cm}$. Bunga jantan memiliki 4 tenda, berwarna putih sampai merah, benang sari kuning. Bunga betina memiliki 5 tenda bunga, merah keputihan. Buah kapsul bersayap 3, berwarna merah, berbulu, beruang 3 dengan sekat, ukuran buah kecil. Kalau matang berwarna coklat dan kering. Jenis ini merupakan jenis yang menjalar dengan ujung batang menaik. Bunganya berwarna merah keputihan dan cocok sebagai tanaman hias dalam pot gantung.
Habitat tumbuh dikawasan hutan primer, naungan penuh, ditemukan pada ketinggian antara 550-1300 m dpl, yang intensitas cahaya rendah, didasar hutan, dekat aliran sungai, tumbuh disela-sela batu. Distribusi: Diketemukan di Resort Balik Bukit dan Pugung tampak kawasan Taman Nasional Bukit Barisan Selatan

\section{h. Begonia muricata Blume}

Pertelaan herba merayap, panjang mencapai $40 \mathrm{~cm}$. Batang licin berbukubuku. Daun bundar telur, pangka lberlekuk menjantung tidak simetris, tepi bergigi halus, ujung meruncing, permukaan atas hijau mengkilat sampai berbulu jarang, bawah daun berbulu dengan urat daun kemerahan, ukuran daun diameter 8-15 $\mathrm{cm}$;tangkai daun 17-33 $\mathrm{cm}$. Tipe perbungaan anak payung menggarpu majemuk; tangkai perbungaan 21-40 $\mathrm{cm}$.Bunga jantan memiliki 4 tenda bunga, putih kemerahan, benang sari kuning, tangkai bunga 1-1,5 cm. Bunga betina memiliki 3 tenda bunga.Buah kapsul, beruang 3 , bersekat, bersayap 3.Jenis ini cukup menarik karena warna bunga kemerahan dan sangat bagus untuk tanaman hias dalampot.

Habitat diketemukan pada ketinggian $950 \mathrm{~m}$ dpl., tumbuh di dasar hutan, bebatuan lembab termasuk batuan kapur di pinggiran sungai, ternaungi. Distribusi di Resort Balik Bukit dan Resort Rigis 45, Taman Nasional Bukit Barisan Selatan

Perbanyakan Begonia relatif mudah. Di habitat alamnya, Begonia umumnya memperbanyak diri secara generatif dengan biji. Dan terkadang juga memperbanyak diri secara vegetatif dengan membentuk plantlet pada daunnya yang jatuh. Dengan demikian jenis ini mudah dikembangbiakkan secara vegetatif dengan cara setek baik setek batang, maupun daun. Perbanyakan secara generatif dengan biji juga tidak terlalu sulit untuk dilakukan. Namun perbanyakan 
vegetatif lebih mudah dan cepat untuk mendapatkan tanaman yang dewasa (Tebbitt, 2005].

\section{Potensi Begonia}

Begonia alam pada umumnya mempunyai bentuk daun yang sederhana dan kurang menarik, akan tetapi ada beberapa jenis Begonia alam bisa dinikmati langsung sebagai tanaman hias, karena bentuk perawakan yang menarik atau habitus merumpun atau daun yang eksotik sehingga sangat potensial untuk dikembangkan sebagai tanaman hias. Berdasarkan hasil pengamatan di lapangan danpenelusuran pustaka, jenis-jenis tumbuhan Begoniaalam di Kawasan Taman Nasional Bukit Barisan Selatan memiliki potensi dan kegunaan yangcukup tinggi. Salah satu potensinya adalah sebagaitanaman hias karena dari jenis yang dikoleksi memiliki morfologi yang cukup menarik terutama pada warna dan corak daun yakni B. atricha,B. isoptera, B.areolata, B.cf. scottii, jenis-jenis ini cocok dijadikan tanaman penghiaspekarangan halaman rumah, karena ukuran cukup besar, warna menarik,bunga kecil dan buah yang unik. Sedangkan jenis B.lepida, B. muricata, dapat dijadikan tanaman hias dalam pot.

Selain berpotensi sebagai tanaman hias, Begonia juga dapat digunakan sebagai bahan makanan dan obat-obatan (Heyne, 1987). B. isoptera dapat digunakan untuk obat pembengkakan limpa. Penduduk di bagian selatan kawasan Taman Nasional Gunung Halimun telah memanfaatkan B. isoptera di atas sebagai lalaban. Ada juga yang menggunakan $B$. robusta dan $B$. multangula sebagai pengganti asam dan menghilangkan bau amis pada ikan. Selain itu, Begonia dapat juga dijadikan makanan penyelamat disaat kita tersesat dalam hutan (Girmansyah, 2008 dan Heyne, 1987). Ada Jenis Begonia yang diketahui mengandung zat yang dapat berfungsi sebagai pencahar atau obat sakit perut. Cairan yang keluar dari batang salah satu jenis Begonia yang berasal dari Asia dapat dipergunakan untuk membersihkan senjata tajam. $B$ glabra berkhasiat sebagai obat untuk menyembuhkan luka baru. Daun, batang dan bunganya mengandung saponin, daunnya mengandung tanin sedangkan batang dan bunganya mengandung flavonoida dan polifenol. B. fimbristipula berkhasiat dapat menurunkan panas atau demam, sebagai obat batuk dan obat sakit pada waktu datang bulan (Tebbitt, 2005). Jenis ini pula yang sudah diolah menjadi minuman segar berupa teh agak pahit dari Cina, minuman tersebut dapat ditemui di Pasar Asia di Amerika.

Penduduk di sekitar kawasan Cagar Alam Batu Karu, Kabupaten Tabanan, Bali mengenal jenis B. baliensis untuk sayur dan obat. Daun dan batang yang masih muda enak dimakan mentah sebagai lalap. Selain sebagai sayuran jenis ini juga banyak dimanfaatkan sebagai obat batuk, masyarakat sekitar memanfaatkan daunnya untuk obat caranya batangnya dikupas ditambahkan daunnya dimasukkan dalam bambu, kemudian bambunya dibakar diatas api, dan cairannya tersebut dipakai sebagai obat batuk (Hartutiningsih H Siregar, Purwantoro, Sudarmono \& Agusta. 2009). Bagi para pecinta alam dan anakanak sekolah yang sedang berkemah di sekitar kawasan danau Buyan dan Tamblingan sudah akrab dengan jenis tumbuhan ini, karena memang diajarkan oleh para pemandu lapangan dalam topik pelajaran jungle survival. Kegunaannya sudah banyak di kenal, sebagai penghilang dahaga dengan cara dikunyah. 


\section{Aspek Konservasi}

Dilihat dari tempat tumbuhnyaBegonia dapat digunakan sebagai tanaman indikatorterhadap kesuburan tanah dan kondisi hutan, karenaBegonia menyukai hutan primer yang mengandungbanyak bahan organik atau serasah (tumpukan daunkering).Berdasarkan potensi dan kegunaan Begonia yang cukup tinggi maka perlu adanya upaya konservasi dan supaya mendapat perhatian khusus untuk dapat dikembangkan di masayang akan datang. Hal dapat dilakukan dengan cara menggali potensi yang lebih jauh lagiuntuk dapat mengetahui apa saja yang terkandung di dalamnya. Dari 8 jenis Begonia yang ditemukan, belum ada data yang akurat mengenai status konservasinya. Sebarannya pun sangat terbatas, sehingga diperlukan tindakan pelestarian yang serius, dikhawatirkan keberadaannya di alam akan makin menyusut seiring dengan tingginya tingkat kerusakan hutan. Disinilah pentingnya usaha konservasi. Dilaporkan bahwa konservasi Begonia alam di Kebun Raya Bogor yang merupakan hasil eksplorasi selama kurun waktu 10 tahun terakhir, koleksi tersebut ditanam sebagai koleksi hidup di Kebun Raya Bogor (Hartutiningsih M. Siregar, 2017). Total 93 nomor koleksi yang terdiri 77 jenis Begonia, 27 jenis diantaranya merupakan jenis-jenis baru yang berhasil diidentifikasi dan dipublikasikan. Hasil eksplorasi yang berasal dari Pulau Sumatera 37 nomor, koleksi dari Taman Nasional Bukit Barisan belum terkoleksi di Kebun Raya Bogor.

$\begin{array}{llr}\text { Kebun } & \text { Raya Liwa sebagai satu } \\ \text { institusi } & \text { yang } & \text { berkewajiban }\end{array}$ mengkonservasi tumbuhan Indonesia merupakan institusi yang tepat untuk menyelamatkan, meneliti dan mengkaji usaha-usaha domestikasinya. Beberapa kegiatan pelestarian eks situ telah dilakukan oleh Kebun Raya Liwa, antara lain adalah menumbuhkembangkan kembali hasil eksplorasi dan inventarisasi.

\section{SIMPULAN}

1. Koleksi Begonia di Taman Nasional Bukit Barisan Selatan yang telah teridentifikasi sampai tingkat jenis ada 8 jenis yakni Begonia atricha (Miq.) Miq. ex A.DC, B. areolata Miq., B.cf. bracteata, B. isoptera Dryand ex. Sm.B.cf. vuijekii Koord, B.cf. scottii Tebbit,. B. lepida Blumedan B. muricata Blume.

2. Seluruh koleksi tumbuhan Begonia keberadaannya di alam sangat terbatas dan akan terancam apabila habitat tempat tumbuhnya terganggu.

3. Hasil eksplorasi Begonia spp. dari Taman Nasional Bukit Barisan Selatan telah dikonservasikan secara eks situ di Kebun Raya Liwa.

4. Koleksi-koleksi Begonia spp. tersebut dapat dijadikan sebagai bahan material hidup untuk penelitian lebih lanjut, baik untuk tanaman obat, tanaman hias maupun tanaman berpotensi ekonomi lainnya.

\section{DAFTAR PUSTAKA}

Dephut. (2011). http://www.dephut. go.id/INFORMASI/TN\%20IND

O-ENGLISH/tnbukitbarisan.htm. Diakses tanggal 1 Maret 2011.

Girmansyah D. (2008). Keanekaragaman Jenis Begonia (Begoniaceae) Liar Dijawa Barat (Biodiversity Of Wild Begonia In West Java). Berita Biologi. 9, (2).2008. 195203.

Hughes M, Girmansyah D, Ardi WH, Nurainas. (2009). Seven new species of Begonia from Sumatera. Gardens Bulletin Singapore 61 (1): 29-44.

Hartutiningsih M.Siregar, Purwantoro RS, Sudarmono \& Agusta A. 
(2009). Pengungkapan potensi obat tiga jenis Begonia terpilih (B. muricata Blume, $B$. multangula Blume, $B$. "Bacem Kebo") melalui uji anti bakteri Escherichia coli dan Staphylococcus aureus secara in vitro. Prosiding seminar nasional sains II. "Peningkatan peran sains dalam pertanian dan industri" Fakultas MIPA, Institut Pertanian Bogor. Bogor. 543551.

Hartutiningsih-M.Siregar. 2017. The Conservation of Native, Lowland Indonesian Begonia Species

Begoniaceae) in Bogor Botanic Gardens. Biodiversitas 18:326333. January 2017 E-ISSN: 2085-4722, 326-333.

Heyne K. 1987. Tumbuhan Berguna Indonesia. Jilid III.Cetakan Ke1, 1463-1464. Badan Penelitian dan Pengembangan Kehutanan. Departemen Kehutanan.Jakarta.

Kiew R. 2005. Begonias of Peninsular Malaysia. Natural History Publications (Borneo). Wisma
Merdeka. Kota Kinabalu, Sabah, Malaysia.

Kiew R, Sang J, Repin R, Ahmad JA. 2015. A guide to Begonias of Borneo. Natural History Publications (Borneo). Wisma Merdeka. Kota Kinabalu, Sabah, Malaysia.

Purwantoro, RS, 2009, Konservasi Tumbuhan Secara Ex Situ Langkah Awal Domestikasi', Prosiding Seminar: Flora Indonesia Dalam Mengatasi Dampak Pemanasan Global. Bedugul, Bali, pp. 81-84.

Rugayah, Widjaja E.A. dan Praptiwi. 2004. Pedoman Pengumpulan data Keanekaragaman Flora. Pusat Penelitian Biologi, Bogor. Indonesia.

Smith LB, Wasshausen, Golding DC, Karegeannes CE. 1986. Begoniaceae. Smithsonian Institution Press. City of Washington. $584 \mathrm{p}$.

Tebbitt MC. 2005. Begonias, cultivation, identification, and natural history. $273 \mathrm{p}$. 